\title{
Cultural competency of nursing faculty teaching in baccalaureate nursing
}

\section{programs in the United States}

\author{
Nadiah A. Baghdadi ${ }^{1}$, Samantha Ismaile ${ }^{1,2}$
}

1. The Collage of Nursing, Princess Nourah bint Abdulrahman University, Saudi Arabia

2. Health Sciences (Nursing) Higher Colleges of Technology, Sharjah, United Arab Emirates

\section{RESEARCH}

Please cite this paper as: Baghdadi N, Ismaile S. Cultural competency of nursing faculty teaching in baccalaureate nursing programs in the United States. AMJ 2018;11(2):126134. https://doi.org/10.21767/AMJ.2018.3335

\section{Corresponding Author:}

Dr. Nadiah Baghdadi

The Collage of Nursing

Princess Nourah bint Abdulrahman University

Riyadh, Saudi Arabia

Email: NABaghdadi@pnu.edu.sa

\section{ABSTRACT}

\section{Background}

Nursing education has acknowledged that cultural competency should be an educational competency of baccalaureate programs. Although nursing faculty are expected to adequately prepare all nurses to provide culturally competent care for patients, the literature suggests that nurse educators' low levels of cultural competence contributes to under-preparation of new nurses to provide culturally competent care.

\section{Aims}

The study assessed nursing faculty cultural competence of teaching at a bachelor of science in nursing programs across the United States and identified demographic factors that are associated with that level.

\section{Methods}

Study used descriptive and correlational design through the use of online questionnaires. The study included $(\mathrm{N}=461)$ nursing faculty across the United States with a response rate of 23 per cent and included 461. Data were collected using a validated tool namely the "Cultural Diversity
Questionnaire for Nurse Educators Revised". Statistical analysis with means and standard deviation were calculated for all continuous variables. For all aims, results were summarized using regression estimates, $\mathrm{p}$-values, and 95 per cent Confidence Interval ( $\mathrm{Cl}$ per cent).

\section{Results}

The Overall Cultural Competence (OCC) mean=166 indicated that nursing faculty has moderate level of cultural competence. The highest index was Cultural Knowledge Subscale $M=43.53$, and the lowest index was Cultural Encounter Subscale $M=22.50$. Regression analysis demonstrated that demographic variables were predictive of the mean score. Transcultural teaching behaviours subscale was considerably low related to the OCC scale, adjusting for all other variables.

\section{Conclusion}

The current study identified previous cultural exposure and cultural education as crucial factors to improve cultural competence. The researchers concluded that faculty cultural training needs to be mandated and should be more inclusive not only of educational material but also to include practice exposure to a diverse population. The training should occur during orientations, practice, and as an annual competency validation.

\section{Key Words}

Nursing faculty, cultural competence, faculty development, nursing instructor, medical education

\section{What this study adds:}

\section{What is known about this subject?}

Nursing education has acknowledged that cultural competency should be an educational competency for students in BSN programs.

\section{What new information is offered in this study?}

Faculty's low level of cultural competency contributes to the students graduating from BSN programs with low level of 
cultural competency. To combat this issue, faculty cultural training needs to be mandated and should be more inclusive not only of educational material but also to include practice exposure to a diverse population.

3. What are the implications for research, policy, or practice?

There is a need for standardised guidelines to assess cultural competence levels among students' and faculty in nursing programs.

\section{Background}

The United States (US) Census Bureau (2012) estimated approximately 37 per cent of the American citizens are classified to ethnic minority groups. ${ }^{1}$ Minority group is a group of individuals who, because of their cultural characteristics and appearances, are excluded from the others in the same society. ${ }^{1}$ by 2043 , they project these groups combined will account for almost half of the American citizens. ${ }^{1}$ As the nation becomes more culturally and ethnically diverse, so does the demand for culturally competent health care. However, the nursing profession does not mirror the diversity of the population it serves. ${ }^{2}$ In order to meet the demands of our diverse society, delivering culturally specific nursing care is no longer a preference, but a requirement. Research demonstrates that the cultural competence level of academic nursing faculty is a major factor in preparing culturally competent students and future nurses. ${ }^{2}$ Nursing faculty need to demonstrate two aspects of cultural competence: faculty must be prepared to teach students from diverse backgrounds and have the ability to teach nursing students how to care for diverse patients. ${ }^{3}$ Researchers have examined the education and abilities of faculty in the culturally competent nursing care and found a serious shortage of adequately prepared faculty. ${ }^{4}$

\section{Aim of the study}

The aim of the research is to assess nursing faculty cultural competence level in the United States. Also, to identify the factors that may influence cultural competence level among nursing faculty who teach a Bachelor in Nursing program in the United States.

\section{Literature review}

Nursing education has acknowledged that cultural competency should be an educational objective of baccalaureate programs. In 2008, the American Association of Colleges of Nursing (AACN) presented a set of competencies crucial for nursing baccalaureate graduates, and provided learning strategies and benchmarks that nurse education programs can use. Despite this, many studies document inconsistent integration of cultural competency into nursing education programs. ${ }^{2,3}$ Ryan, et al. in 2000, Identified barriers to strengthening the presence of cultural competency in nurse education curricula include the faculty's lack of multicultural experience and the lack of room for new material in an already full educational program.

\section{Cultural competency of nursing educators}

Although nursing educators are expected to educate nursing students to provide culturally proficient care for patients, the literature suggests that nurse educators' low levels of cultural competence contribute to underpreparation of new nurses to provide culturally competent care. $^{2,4-8}$ Low levels of nursing faculty cultural competence suggests that nursing faculty are not well prepared to respond to issues related to cultural diversity in health care, or to educate nursing care from culturally competent. ${ }^{4,9,10}$ Literature strongly suggests that strengthening the cultural competence of nursing educators is vital to prepare our future nurses. ${ }^{8}$

Moreover, research acknowledges the lack of nursing educators with sufficient transcultural nursing knowledge, attitudes, and behaviours that can teach culturally competent nursing care and care for patients from diverse backgrounds. ${ }^{4,9-12}$ The lack of minority nursing educators that represent the ethnic and racial minority groups living in the United States also contributes to the problem. ${ }^{13}$ Nursing educators from diverse ethnic backgrounds act as leaders in the growth of care models that tackle the unique needs of racially and ethnically diverse populations. ${ }^{14}$ This is done through role modelling of cultural awareness, knowledge, and skills. ${ }^{10-14}$ Indeed, having nursing educators from diverse backgrounds will result in better educational experiences for nursing students. ${ }^{15}$ According to the literature, nurses faces challenges when providing care to patients with other cultural backgrounds. ${ }^{16}$ These challenges may include lack of transcultural skills and task, educational background and comfort to effectively care for patients from diverse cultural backgrounds. ${ }^{16}$ Moreover, barriers to cultural competency include the shortages in nursing educators, aging of nursing educators, under-preparation of educators to teach cultural diversity issues, and lack of educators awareness on transcultural skills and task. ${ }^{17,18}$ The Process of Cultural Competence in the delivery of healthcare services model provides the organizing framework for this study. ${ }^{19}$ According to this model, the process of cultural competence comprises five interconnected concepts that represent an interdependent relationship. ${ }^{19}$ Accordingly, The aim of this 
study is to assess the level of cultural competence of nursing educators in teaching Bachelor of Science in Nursing (BSN) program in the United States. Also, it will identify factors that influence nursing educator's cultural competence level.

\section{Method}

The aim of the study is to measure the level of cultural competence among nursing educators teaching in the U.S. and to recognize and inspect demographic factors that may influence the cultural competence level.

\section{Research design}

A descriptive, correlational, non-experimental, design was used to guide the study by the use of online questionnaire.

\section{Sample}

The sample included nursing educators teaching in accredited BSN program in the United States.

The inclusion criteria for the study sample were: 1) Nursing faculty members actively teaching in baccalaureate nursing programs; 2) Nursing faculty teaching in class, clinical, online, or laboratory settings; 3 ) Nursing faculty teaching in generic (entry-level) baccalaureate nursing programs; and 4) Nursing faculty teaching as full time, part time, or as adjunct staff. The Exclusion criteria were: 1) Nursing faculty teaching non-generic forms of BSN programs; and 2) Nursing faculty that only held administrative, non-teaching positions.

\section{Ethical approval}

Northeastern University Institutional Review Board (IRB) approved this research project prior to its initiation (IRB\#1207-11). A Northeastern University consent form for online surveys was uploaded as a prerequisite to initiating the survey.

\section{Instrument}

The primary instrument for this study was the, "Cultural Diversity Questionnaire for Nurse Educators Revised" CDQNE- $R{ }^{7,20}$ was used with permission from original authors. The first section of the CDQNE-R is forty-one questions organized into five subscales cultural awareness subscale; cultural knowledge subscale; cultural skills subscale; cultural encounters subscale; and cultural desire subscale. Eleven items on the CDQNE-R were selected by Sealey in $\mathbf{2 0 0 3}$ from the five subscales to form transcultural teaching behaviours subscale. ${ }^{7}$ Items that form the transcultural teaching behaviours subscale are embedded within the other five subscales. The second section of the instrument includes demographic and professional questions. These questions were modified from the original survey to meet the current study needs includes 18 questions; four additional questions address participants' exposure to other cultures, fluency in language other than English, getting cultural competence training, and level of cultural content in their current teaching programs. Internal validity was tested by the primary author of the instrument. $^{7,21}$ For the current study, the reliability coefficient for the overall CDQNE-R scale was $\alpha=0.94$. The reliability coefficient for the subscales ranged from $\alpha=0.75-$ 0.87 respectively, that indicates a high level of internal consistency.

\section{Data collection}

Data was collected using the CDQNE-R online survey through the SurveyMonkey website. The study invitation was sent to 2,404 potential participants' email accounts that were obtained from the selected schools websites. After the deletions and exclusions, study reminders were resent to the remaining 2,092 email addresses. To maximize response rate, the researcher sent four email reminders. A total of 461 questionnaires were completed, for a 23 per cent response rate.

\section{Data analysis}

Statistical analysis was done with SAS 9.3C (SAS Institute Inc., Cary, NC). All tests were 2-sided, with $P<0.05$ as statistically significant. Demographic characteristics, as well as scale analysis were compared using two-tailed t-tests for two independent samples, and $\chi 2$ test for differences in proportion. Means and standard deviation were calculated for all continuous variables. For all aims, results were summarized using regression estimates, p-values, and 95 per cent confidence interval ( $\mathrm{Cl}$ per cent).

\section{Results}

\section{Demographic Characteristics}

According to Table 1, the majority of the participants identified themselves as Caucasian ( $n=383,87.44$ per cent). Followed by African American ( $n=14,3.2$ per cent), Hispanic ( $n=11,2.51$ per cent), Asian ( $n=7,1.6$ per cent), American Indian/Alaskan Native ( $n=3,0.68$ per cent), Native Hawaiians/Pacific Islander ( $n=1,0.23$ per cent). Eight participants declined to state their race (1.83 per cent), and 11 participants identified their race as "other" (2.51 per cent). The majority of the participants were between the ages of 51 and $60(n=162,36.99$ per cent), female $(n=402$, 91.78 per cent).

More than 32.65 per cent of the participants have been teaching for over 15 years $(n=143)$, more than half of the 
participants ( $n=242,55.25$ per cent) listed master degree as their highest degree earned. Majority of participants were full-time faculty ( $n=397,91.47$ per cent), 240 participants reported that they are working at public institutions (87.59 per cent); and currently teach in undergraduate nursing programs ( $n=424,97.7$ per cent).

Majority of the participants ( $n=336,76.71$ per cent) have not lived outside of the U.S. for more than 6 months. There were 254 participants who reported attending a continuing education program on transcultural nursing/cultural competence in the past five years (58.53 per cent); the majority of participants included cultural content in their current teaching program ( $n=423,97.47$ per cent). More than half of the participants reported that they fully integrate cultural content in their current program ( $n=246$, 56.68 per cent).

Cronbach alpha coefficient was applied to determine the internal consistency of the subscales and the overall CDQNE-R. The reliability coefficient for the subscales ranged from $\alpha=0.75-0.87$ respectively. All values indicate a good level of reliability. The reliability coefficient for the overall CDQNE-R scale was $\alpha=0.94$, this value indicates a high level of internal consistency.

\section{Overall cultural competence level of participants}

According to Table 2, all responses were added to calculate the mean of the overall Cultural Competence Scale and 6 subscales. The metric by Ume-Nwagbo in $2009^{22}$ was used to classify the overall level of cultural competence based on survey results (55-130=low level, 131-201=moderate level, 202-275=high level). The results showed that more than 90 per cent of the sample had a moderate cultural competence level $(n=421)$ with a mean $166.3 \pm S D=19.5$. Table 3, describes the overall cultural competence level of the sample according to the metric described above. The highest indices were the Cultural Knowledge Subscale with a mean $=43.53 \pm S D=6.2$ and the Cultural Teaching Behavior Subscale with a mean $=42.1 \pm S D=4.1$. The lowest indices were the Cultural Skills Subscale with a mean $=31.53 \pm S D=4.41$, and the Cultural Encounter Subscale with a mean $=22.50 \pm S D=4.42$.

According to Table 3, to evaluate the different contributing factors, a multiple linear regression model was used to calculate estimates of regression coefficients, standard error, and the $p$-value controlling for gender, age group, and race. The overall regression is statistically significant with the probability of the $F$-test $<0.0001$. Our model has predicting capability reaching 40 per cent of the variability in overall cultural competence score $(R 2=0.39)$. Table 3 shows that all listed predictors were statistically significant $(P$-value $<0.05)$ adjusting for race, age group, and gender.

According to Table 4, evaluation of the transcultural nursing concepts in teaching using the multiple linear regression models demonstrated the overall regression is statistically significant to the probability of the F-test $<0.0001$. The model showed that with adjustments for all other variables, the transcultural teaching behaviors subscale was significantly associated with the overall cultural competence mean score $(p<0.0001)$. The model also had predicting capability reaching 86 per cent of the variability in overall cultural competence score $(R 2=0.86)$. In other words, the transcultural teaching behaviors subscale was a critical predictor of the overall cultural competency score of participants. Participants who used transcultural teaching behaviors had 3.3 points \pm 0.01 higher overall cultural competency mean scores than those who did not.

\section{Discussion}

According to the results, nurse educators have a moderate level of cultural competence. Studies have found that nurse educators with higher levels of cultural competence were more likely improve student's awareness of culturally diverse skills and tasks and to feel more comfortable providing nursing care to clients from diverse cultural backgrounds. ${ }^{5-7,20,21}$ A number of studies, however, have reported different findings. For example, a study by Sealey at el., measured the cultural competence level of nursing faculty in Louisiana and found that participants fell below expectations to teach and care for individuals from diverse backgrounds. ${ }^{7}$ Another study by Yates, highlighted the importance of hiring and retaining culturally diverse nurse educators. $^{20}$ They also stress on the value of providing professional development programs for educaters. ${ }^{20}$ Similar finding to this study was reported by other schoolers. ${ }^{21}$

This interesting inconsistency of the findings of several studies could be the result of many factors. For example, all the mentioned studies were conducted at state level limiting the comparison with the current study that was conducted nationally. Location of nursing schools where studies were conducted also could influence the cultural competence of participants. For instant, participants who live in states with high immigration rates would have more exposure to individuals from diverse backgrounds than participants who live in states with low immigration rates. This factor might influence their cultural competence level.

Contributing Factors to Cultural Competence Level Study 
findings highlighted that although strong relationships were not demonstrated between predictors and the overall cultural competence score, there were significant correlations between some predictors on the overall cultural competence score. Those predictors were race and ethnicity, teaching experience, resided in different culture more than six months, language spoken other than English, nursing specialty, highest degree achieved, cultural continuing education in the past five years, and assessing student needs. Those predictors also positively influenced the mean of the overall cultural competence score after adjusting for sample gender and age.

Some findings are consistent with previous studies that examined factors influenced cultural competence level of nurses. However, those factors were not tested in one study. For instance, most studies identified higher levels of education; studies based on participants who had received continuing cultural education showed significantly higher scores for cultural competence behaviors. ${ }^{7,21-23}$ Cultural competence behaviors are defined as "the ongoing process in which the healthcare professional continually strives to achieve the ability and availability to work effectively within the cultural context of the patient (family, individual or community". ${ }^{15}$ This implies that nurses' cultural competence develops not only from practice, but also from nursing education. Other studies identified nursing working experience has a positive influence on the cultural competence level of nurses. ${ }^{22,24}$ Those studies found that nurses who had more work experience were more competent caring for clients from different cultural and ethnic backgrounds. Other studies found that exposure to culturally and ethnically diverse populations portray an important role in improving cultural competence levels. ${ }^{7,21,25,26}$

Finally, Transcultural Teaching Behaviors findings highlight a strong relationship with adjustment for all other variables. The findings highlight that faculty commitment to transcultural teaching behaviors acts as a motivator toward pursuing cultural competency.

\section{Limitations}

This study is a descriptive correlational design, which can only show the relationship between and among variables. The researcher cannot establish causality. This design also requires large sample size and large variance to determine the existence of a relationship.
This study highlights inconsistency in cultural competence level in nurse educators. This suggests that nurse educators are not well prepared to respond to issues related to cultural diversity. For instance, the diversity can be based on gender, race, ethnicity, sexual orientation, and social status. The findings of this study have important implications for cultural competence of nurse educators. The researcher's assessment of the study population is that there is improvement of the cultural competence level from previous studies. Yet, there is a major lack in cultural competence training and workshops for nurse educators.

Finally, the current study identified previous cultural exposure and cultural education as crucial factors to improve cultural competence. It is suggested that nurse educators cultural training needs to be mandated and should be more inclusive not only of educational material but also to include practice exposure to a diverse population. The training should occur during orientations, practice, and as an annual competency validation.

\section{References}

1. Department of Commerce. U.S. Census Bureau. U.S. Census Bureau Projections Show a Slower Growing, Older, More Diverse Nation a Half Century from Now. December, 2012.

2. Kardong-Edgren S. Cultural competence of Baccalaureate nursing faculty. J Nurs Educ. 2007;46(8):360-366.

3. Moyer B, Wittmann-Prince R. Nursing education: Foundations for practice excellence. Philadelphia: F.A. Davis Company;2008.

4. Ryan M, Carlton K, Ali N. Transcultural nursing concepts and experiences in nursing curricula. J Transcult Nurs. 2000;11(4):300-307.

5. Kardong-Edgren S, Bond ML, Schlosser S, et al. Cultural attitudes, knowledge, and skills of nursing faculty toward patients from four diverse cultures. J Prof Nurs. 2005;21(3):175-182.

6. Mayo RM, Sherrill WW, Sundareswaran $P$, et al. Attitudes and perceptions of Hispanic patients and health care providers in the treatment of Hispanic patients: a review of the literature. Hisp Health Care Int. 2007;5(2):64-72.

7. Sealey LJ, Burnett M, Johnson G. Cultural competence of baccalaureate nursing faculty: are we up to the task? J Cult Divers. 2006;13(3):131-140.

8. Sealey $L$. Cultural competence of faculty of baccalaureate nursing programs. Doctoral dissertation, Louisiana State University and Agricultural \& Mechanical College. 2003.

\section{Conclusion}


9. Grant LF, Letzring TD. Status of cultural competence in nursing education: a literature review. J Multicult Nurs Health. 2003;9(2):6-13.

10. Wells MI. Beyond cultural competence: A model for individual and institutional cultural development. J Community Health Nurs. 2000;17(4):189-199.

11. American Association of Colleges of Nursing. Cultural Competency in Baccalaureate Nursing Education. 2008. Retrievedfromhttp://www.aacn.nche.edu/leadinginitiati ves/educationresources/competency.pdf

12. American Association of Colleges of Nursing. Nursing Faculty Shortage Fact Sheet. 2014.Retrieved from http://www.aacn.nche.edu/media-relations/factsheets/nursing-facultyshortage

13. The National League for Nursing and the Carnegie Foundation. NLN Nurse Educator Shortage Fact Sheet. The National League for Nursing. 2010. Retrieved from http://www.nln.org/governmentaffairs/pdf/nursefaculty shortage.pdf

14. Byrne $M$, Weddle $C$, Davis $E$, et al. The Byrne guide for inclusionary cultural content. J Nurs Educ. 2003;42(6):277.

15. Campinha-Bacote J. Coming to Know Cultural Competence: An Evolutionary Process. Int J Hum Caring. 2011;15(3);42-48.

16. Coffman M, Shellman J, Bernal H. An integrative review of American nurses' perceived cultural self-efficacy. J Nurs Scholarsh. 2004;36(2):180-185.

17. American Association of Colleges of Nursing. Enrolment and Graduations in Baccalaureate and Graduate Programs in Nursing. 2013. Retrieved from:

http://www.aacn.nche.edu/news/articles/2012/enrollm ent-data

18. Mena JA, Rogers MR. Factors associated with multicultural teaching competence: Social justice orientation and multicultural environment. Train Educ Prof Psychol. 2017;11(2):61-68.

19. Campinha-Bacote, J. The process of cultural competence in the delivery of healthcare services. 2010. Retrieved from

www.transculturalcare.net/Cultural_Competence_Mode I.htm

20. Yates VM. Cultural competence levels of Ohio associate degree nurse educators. Unpublished Ph.D., ProQuest Information \& Learning, U.S. 2009

21. Ume-Nwagbo PN. Relationship between nurse educators' cultural competence and ethnic minority nursing students' recruitment and graduation. Unpublished doctoral dissertation, ProQuest Information \& Learning, US.2009

22. Lampley TM, Little KE, Beck-Little R, et al. Cultural competence of North Carolina nurses: a journey from novice to expert. Home Health Care Manag Pract. 2009;20(6):454-461.

23. Schim SM, Doorenbos AZ, Borse NN. Cultural competence among Ontario and Michigan healthcare providers. J Nurs Scholarsh. 2005;37(4):354-360.

24. Hagman LW. Cultural self-efficacy of licensed registered nurses in New Mexico. J Cult Divers. 2006;13(2):105112.

25. Liu L, Mao C, Barnes-Willis LE. A. Cultural self-efficacy of graduating baccalaureate nursing students in a state funded university in the Silicon Valley. J Cult Divers. 2008;15(3):100-107.

26. Marzilli C. Mastel-Smith B. Cultural competence of prelicensure nursing faculty. J Nurs Educ Pract. 2017;7(9):90-97

\section{ACKNOWLEDGEMENTS}

Ministry of Education, Princess Nourah Bint Abdulrahman University for Doctorate PhD in Nursing Scholarship. Saudi Cultural Mission ID\# 56810. Elizabeth P. Howard, PhD, MSN, FAAN, Associate Professor, School of Nursing, Northeastern University, Boston, USA. Aziza Jamal-Allial. PhD. Researcher at Safety and Epidemiology, HealthCare, Inc. Boston, USA.

\section{PEER REVIEW}

Not commissioned. Externally peer reviewed.

\section{CONFLICTS OF INTEREST}

The authors declare that they have no competing interests.

\section{FUNDING}

Ministry of Education, Princess Nourah Bint Abdulrahman University for Doctorate PhD in Nursing Scholarship. Saudi Cultural Mission ID\#56810

\section{ETHICS COMMITTEE APPROVAL}

Northeastern University Institutional Review Board (IRB\# 12-07-11. 
Table 1: Demographic characteristics of the sample

\begin{tabular}{|c|c|c|c|}
\hline Characteristics & $\mathbf{N}$ & $\%$ & P-value \\
\hline Age group & & & $<0.0001$ \\
\hline $20-30$ years & 8 & 1.83 & \\
\hline $31-40$ years & 43 & 9.82 & \\
\hline $41-50$ years & 123 & 28.08 & \\
\hline $51-60$ years & 162 & 36.99 & \\
\hline 61 and above & 101 & 23.06 & \\
\hline Decline & 1 & 0.23 & \\
\hline Gender & & & $<0.0001$ \\
\hline Male & 30 & 6.85 & \\
\hline Female & 402 & 91.78 & \\
\hline Decline & 6 & 1.37 & \\
\hline Race & & & $<0.0001$ \\
\hline Caucasian & 383 & 87.44 & \\
\hline African American/African & 14 & 3.2 & \\
\hline Hispanic & 11 & 2.51 & \\
\hline Asian & 7 & 1.6 & \\
\hline American Indian/Alaskan Native & 3 & 0.68 & \\
\hline Native Hawaiian/Pacific Islander & 1 & 0.23 & \\
\hline Decline to state & 8 & 1.83 & \\
\hline Other & 11 & 2.51 & \\
\hline Resided in different Culture $>6$ months & & & $<0.0001$ \\
\hline No & 336 & 76.71 & \\
\hline Yes & 102 & 23.29 & \\
\hline Language other than English & & & $<0.0001$ \\
\hline No & 372 & 84.93 & \\
\hline Yes & 66 & 15.07 & \\
\hline Teaching Nursing Experience & & & $<0.0001$ \\
\hline Less than one year & 16 & 3.65 & \\
\hline $1-5$ years & 94 & 21.46 & \\
\hline $6-10$ years & 130 & 29.68 & \\
\hline $10-15$ years & 55 & 12.56 & \\
\hline More than 15 years & 143 & 32.65 & \\
\hline Highest Degree Attained & & & $<0.0001$ \\
\hline Bachelors & 6 & 1.37 & \\
\hline Masters & 242 & 55.25 & \\
\hline DNP & 27 & 6.16 & \\
\hline $\mathrm{PhD}$ & 145 & 33.11 & \\
\hline Ed.D. & 18 & 4.11 & \\
\hline Employment Status & & & $<0.0001$ \\
\hline Full-time & 397 & 91.47 & \\
\hline Part-time & 22 & 5.07 & \\
\hline Adjunct & 10 & 2.3 & \\
\hline Other & 5 & 1.15 & \\
\hline Type of Institution & & & $<0.0001$ \\
\hline Public College & 240 & 87.59 & \\
\hline Private College & 22 & 8.03 & \\
\hline Both & 12 & 4.38 & \\
\hline Level of Nursing Program Teach. & & & $<.0001$ \\
\hline Graduate & 2.3 & 10 & \\
\hline Undergraduate & 97.7 & 424 & \\
\hline Cultural Continuing Education & & & 0.0004 \\
\hline No & 180 & 41.47 & \\
\hline Yes & 254 & 58.53 & \\
\hline
\end{tabular}




\begin{tabular}{|l|c|c|c|}
\hline Including Cultural Content in Current Program & & & $<0.0001$ \\
\hline No & 11 & 2.53 & \\
\hline Yes & 423 & 97.47 & \\
\hline Level of Cultural Content in Current Program & & & $<0.0001$ \\
\hline Fully Integrated & 246 & 56.68 & \\
\hline Occasionally mentioned & 133 & 30.65 & \\
\hline Required course & 44 & 10.14 & \\
\hline Elective course & 11 & 2.53 & \\
\hline Assess Students' Cultural Beliefs & & & 0.05 \\
\hline No & 197 & 45.39 & \\
\hline Yes & 237 & 54.61 & \\
\hline
\end{tabular}

Data were presented as $\mathrm{N}=$ total, $\%=$ percentage, $\mathrm{p}$-values were compared using chi-square test

Table 2: Cultural diversity questionnaire for nurse educators revised subscales mean and scores

\begin{tabular}{|l|c|c|c|c|c|c|c|c|}
\hline \multicolumn{1}{|c|}{ Scale } & Mean & SD & SE & Min & Max & Item & $\begin{array}{c}\text { Poss } \\
\text { Mini }\end{array}$ & $\begin{array}{c}\text { Poss } \\
\text { Max }\end{array}$ \\
\hline Awareness & 35.2 & 3.51 & 0.17 & 20 & 40 & 8 & 8 & 40 \\
\hline knowledge & 43.5 & 6.21 & 0.29 & 17 & 55 & 11 & 11 & 55 \\
\hline Skills & 31.5 & 4.41 & 0.21 & 13 & 40 & 8 & 8 & 40 \\
\hline Encounter & 22.5 & 4.42 & 0.21 & 11 & 30 & 6 & 6 & 30 \\
\hline Desire & 33.5 & 4.11 & 0.19 & 15 & 40 & 8 & 8 & 40 \\
\hline Teaching & 42.1 & 4.99 & 0.24 & 24 & 50 & 11 & 11 & 55 \\
\hline Competence & 166.3 & 19.53 & 0.93 & 86 & 204 & 41 & 41 & 205 \\
\hline
\end{tabular}

Mean values based on the response scale 1=strongly disagree, 2=disagree, 3=undecided, 4=agree, 5=strongly agree. SD: standard deviation. SE: standard error. Min: Minimum. Max: Maximum. Items: items for each subscale. Poss. Mini. Possible minimum answers for each subscale. Poss. Max. Possible maximum answers for each subscale

Table 3: Regression estimate of overall cultural competence score contributing factors

\begin{tabular}{|c|c|c|c|c|c|c|c|}
\hline Source & DF & \multicolumn{2}{|c|}{ Sum of Squares } & \multicolumn{2}{|c|}{ Mean Square } & F Value & $\operatorname{Pr}>\mathrm{F}$ \\
\hline Model & 21 & \multicolumn{2}{|c|}{59682.8715} & \multicolumn{2}{|c|}{2842.0415} & 11.46 & $<.0001$ \\
\hline Error & 379 & \multicolumn{2}{|c|}{93967.9714} & \multicolumn{2}{|c|}{247.9366} & & \\
\hline $\begin{array}{l}\text { Corrected } \\
\text { Total }\end{array}$ & 400 & \multicolumn{2}{|c|}{153650.8429} & & & & \\
\hline R-Square & \multicolumn{3}{|c|}{ Coefficient Variance } & \multicolumn{2}{|c|}{ Root MSE } & \multicolumn{2}{|c|}{$\begin{array}{l}\text { Cult_Compet_Scale } \\
\text { Mean }\end{array}$} \\
\hline 0.388432 & \multicolumn{3}{|c|}{9.449345} & \multicolumn{2}{|l|}{15.746} & \multicolumn{2}{|l|}{166.6359} \\
\hline \multicolumn{3}{|l|}{ Predictor } & \multicolumn{2}{|l|}{ Estimate } & SEM & \multicolumn{2}{|l|}{ P-value } \\
\hline \multicolumn{8}{|c|}{ Reside Diff. Country } \\
\hline \multicolumn{3}{|l|}{ No } & \multicolumn{2}{|l|}{-4.71} & 2.05 & \multicolumn{2}{|l|}{0.022} \\
\hline \multicolumn{8}{|l|}{ Yes } \\
\hline \multicolumn{8}{|c|}{ Other Languages } \\
\hline \multicolumn{3}{|l|}{ No } & \multicolumn{2}{|l|}{-6.225} & 2.5 & \multicolumn{2}{|l|}{0.012} \\
\hline \multicolumn{8}{|l|}{ Yes } \\
\hline \multicolumn{8}{|c|}{ Highest Degree } \\
\hline \multicolumn{3}{|c|}{ A-Bachelors/Masters } & \multicolumn{2}{|l|}{-5.094} & 1.7 & \multicolumn{2}{|l|}{0.002} \\
\hline \multicolumn{8}{|c|}{ DNP/PhD/Ed.D. } \\
\hline \multicolumn{8}{|l|}{ Specialty } \\
\hline \multicolumn{3}{|l|}{ Adult Health } & -9.0521 & & 3 & 0.002 & \\
\hline Cultural Educ & & & & & & & \\
\hline No & & & -5.224 & & 1.8 & 0.002 & \\
\hline Yes & & & & & & & \\
\hline Teach Cultur & onten & & & & & & \\
\hline No & & & -25.478 & & 6.3 & $<0.0001$ & \\
\hline Yes & & & & & & & \\
\hline
\end{tabular}




\begin{tabular}{|l|l|l|l|}
\hline Assess Student Culture & & & \\
\hline No & -13.192 & 1.6 & $<0.0001$ \\
\hline Yes & & & \\
\hline
\end{tabular}

Estimate, SEM and P-values were calculated using PROC GLM. All covariates were included in the model simultaneously, including Age group, race, gender, Reside in another country, Language other than English, Highest degree attained, Teaching cultural content, Specialty, Continue cultural education, Assess students' cultural needs

Table 4: Regressions estimate of transcultural teaching behaviours relation to the overall cultural competence level

\begin{tabular}{|l|l|l|l|l|l|}
\hline Source & DF & $\begin{array}{l}\text { Sum of } \\
\text { Squares }\end{array}$ & Mean Square & Value & $\operatorname{Pr}>$ F \\
\hline Model & 22 & 132223.9 & 6010.17 & 106.03 & $<0.0001$ \\
\hline Error & 378 & 21426.8 & 56.68 & & \\
\hline $\begin{array}{l}\text { Corrected } \\
\text { Total }\end{array}$ & 400 & 153650.8 & & & \\
\hline R-Square & $\begin{array}{l}\text { Coefficient } \\
\text { Variance }\end{array}$ & Root MSE & Root MSE & Mean \\
\hline $\begin{array}{l}\text { 0.860548 } \\
\text { Variable }\end{array}$ & 4.518197 & 7.528938 & 7.528938 & 166.6359 \\
\hline Estimate & SEM & SEM & $\boldsymbol{P}$-value \\
\hline
\end{tabular}

Estimate, SEM and P-values were calculated using PROC GLM; The model was adjusted for race, gender, age group, resided in another country, other language, highest degree attained, specialty, cultural education, teaching cultural content, and assess students' cultural needs. 